International Journal of Mechanical Engineering and Technology (IJMET)

Volume 11, Issue 9, September 2020, pp. 33-37, Article ID: IJMET_11_09_004

Available online at https://iaeme.com/Home/issue/IJMET?Volume=11\&Issue=9

ISSN Print: 0976-6340 and ISSN Online: 0976-6359

DOI: https://doi.org/10.34218/IJMET.11.9.2020.004

(C) IAEME Publication

Scope Database Indexed

\title{
REVIEW PAPER - THE EFFECT OF INTERNALLY HELICALLY RIBBED TUBES ON THE HEAT TRANSFER COEFFICIENT AND FRICTION FACTOR
}

\author{
G. Bhasker \\ Design Engineer, Clair Engineers Pvt Ltd, Hyderabad, India
}

A.V. Sita Rama Raju

Professor, Department of Mechanical Engineering, CVSR College of Engineering, Anurag Group on Institutions, Venkatapur, Hyderabad, India

\begin{abstract}
This paper presents enhancing the heat transfer for the fluid flow the internally helically ribbed tubes because of extended geometry by increasing the convective heat transfer coefficient as compared to smooth tubes. Due to the presence of ribs inside the tube the friction factor has increased because of increase in the surface contact area between the fluid and solid material. The extended ribbed surface changes the flow direction of fluid to turbulent even at low Reynolds number. Due to the presence of ribs inside the tube or an extended surface it becomes difficult to find the heat transfer coefficient analytically. Therefore the experiments are carried out to determine the heat transfer coefficient for internal helical ribs presents inside the tube. Therefore various authors' puts forward for modelling thermal and flow conditions in internal ribbed tubes.
\end{abstract}

Keywords: friction factor, heat transfer coefficient, helically internally ribbed tubes.

Cite this Article: G. Bhasker and A.V. Sita Rama Raju, Review Paper - The Effect of Internally Helically Ribbed Tubes on the Heat Transfer Coefficient and Friction Factor. International Journal of Mechanical Engineering and Technology. 11(9), 2020, pp. 33-37.

https://iaeme.com/Home/issue/IJMET?Volume $=11 \&$ Issue $=9$

\section{INTRODUCTION}

The importance of this paper is to explain the previous work carried out and contribution towards increase the heat transfer. A heat exchanger is a device that facilitates the heat transfer between hot and cold mediums. Several types of heat exchangers have been developed for different purposes with varied sizes as steam power plants, refrigerators, 
chemical processing plants, air conditioning so on. In most of heat exchangers like in shell and tube heat exchangers the heat transfer takes place by conduction and convection. In water tube boilers, the water flows through tubes whereas the hot combustion gas surrounds the tubes. In order to generate the superheated steam the water has to flow through the evaporator (heat exchanger) of the boiler. The design of heat exchanger is very critical. The heat exchanger design includes finding the quantity of heat transfer rate, pressure drop; estimation of performance, sizing and cost plays vital roles in the design. The cost of heat exchanger is very much important in power plants and chemical processing plants. The weight and size of heat exchanger plays vital role in space and aeronautical applications.

The main purpose of internal helical ribs in tubes is to change the structure of the fluid flow, which turns into helical. Thus it make possible to restrict the tube wall temperature because of boiling crisis. The helical rib induces the centrifugal force that makes the fluid droplets throw onto the tube wall. Hence continuously water film is kept on the tube surface which makes the advantage of preventing the boiling crisis. Therefore the tubes of evaporator can protect from reaching the maximum limit steel temperature. Because of this reason the heat exchangers which are exposed to high heat fluxes their tubes are made with internal helical ribs. The tube with internal helical ribs finds application in supercritical circulating Fluidized (CFB) boiler.

The convective heat transfer coefficient variation depends on the rib area and the rib surface. Many studies are carried out to find the effect of rib height, rib width, pitch, and rib cross section on fluid flow and heat transfer characteristics.

\section{LITERATURE REVIEW}

Carnavos [1] was the first studied the effect of ribs inside the tubes. He has done the experiments and presented the testing results while cooling of air. The analysis is carried out by taking 21 tubes. The inner diameter of tubes varied from 3.18 to $23.8 \mathrm{~mm}$. The tubes analysed having 5 to 41 ribs of different geometry. Also helix angle of ribs varied from $0^{\circ}$ to $20^{\circ}$. The results showed that the heat transfer coefficient is related to the helix angle and ribs geometrical dimensions. The results revealed that by using the tubes with internal ribs will reduce the number of tubes required in the heat exchanger. Also the power of the heat exchanger has been increased without increasing the mass flow rate of medium.

Webb [2] studied by taking the water with Prandtl numbers varies from $5.08-6.29$ through the seven rifled tubes having internal helical ribs with inner diameter $15.54 \mathrm{~mm}$. Each tube having 18 to 45 ribs with helix angle ranges from $25^{\circ}$ to $45^{\circ}$ and height of ribs ranges from 0.33 to $0.5 \mathrm{~mm}$. The experimental measurements lead to formulate correlations that enable calculations of friction factor and the Chilton-Colburn $j$ factor. By knowing the $\mathrm{j}$ factor and with the help of Nusselt and Stanton non dimensional numbers, the heat transfer coefficient is calculated.

He has used the relation to determine the dimension less Chilton-Colburn $j$ factor for internally ribbed tubes.

$$
j=0.00933 R e^{-0.181} N^{0.285}\left(\frac{e}{d_{i}}\right)^{0.323} \beta^{0.505}
$$

Zdaniuk's [3] studied the effect of water flow through the internal helical ribbed tubes. The helix angle and the number of ribs range from $25^{\circ}$ to $48^{\circ}$ and 10 to 45 . The tubes used in experiments having outer diameter $18.8 \mathrm{~mm}$ with wall thickness $0.7 \mathrm{~mm}$. The rib height takes from 0.31 to $0.51 \mathrm{~mm}$. The data obtained is compared with Ditus-Boelter equations to calculate heat transfer rate. 
He has used the relation to determine the dimension less Chilton-Colburn $j$ factor for internally ribbed tubes.

$$
\begin{aligned}
& j=0.029 R e^{-0.347} N^{0.253}\left(\frac{e}{d_{i}}\right)^{0.0877} \beta^{0.362} \\
& j=0.0206 R e^{-0.219} N^{0.220}\left(\frac{e}{d_{i}}\right)^{0.486} \beta^{0.544}
\end{aligned}
$$

Where $\mathrm{N}=$ number of ribs, e $(\mathrm{mm})=$ height of rib, $\mathrm{d}_{\mathrm{i}}(\mathrm{mm})=$ inner diameter(ribs omitted) and $\beta\left(^{\circ}\right)=$ helix angle of rib.

Pan [4] studied the effect of water flow through the vertical rifled tubes. The pressure and heat flux used in experiment range from 12 to $30 \mathrm{MPa}$ and 133 to $719 \mathrm{~kW} / \mathrm{m}^{2}$. The inner diameter of tubes was $20 \mathrm{~mm}$ with ribs height $0.92 \mathrm{~mm}$ and pitch $19 \mathrm{~mm}$ with helix angle of $39.5^{\circ}$. The results obtained from the experiments are the wall temperature calculations at different fluid pressure and local heat transfer coefficient for various values of heat flux.

Zhu [5] In this paper it is studied the phenomenon of self-compensation for flow of water through the rifled tubes arranged in parallel having the tubes having hydraulic diameter of $15.24 \mathrm{~mm}$.

Li [6] and Yang [7] in this paper it is presented the numerical calculations of the convective heat transfer coefficient for supercritical $\mathrm{CO}_{2}$ flowing through vertical rifled tubes. It is observed the rib helix angle has effect on wall temperature and fluid velocity. In both cases, the inner diameter less than $20 \mathrm{~mm}$ is considered.

Xu [8] this paper presented determination of heat transfer coefficient for Therminol 55 (Synthetic heat transfer fluid) in an internally ribbed tube. The inner and outer diameter of tube taken as 14.2 and $28.8 \mathrm{~mm}$ with rib height of $0.85 \mathrm{~mm}$ and helix angle of $54^{\circ}$ and four numbers of ribs were used.

Zhang [9] the supercritical water is used to flow through vertical electrically heated tube for upward flow. The length of tube which is heated was $2510 \mathrm{~mm}$ long. The inner and outer diameter of tube were 20.62 and $33.4 \mathrm{~mm}$ with number of ribs 6 , rib helix angle of $50^{\circ}$, and height of rib $1.25 \mathrm{~mm}$. Lot of work has been carried out to develop a new correlation that enables the calculation of heat transfer coefficient.

Slawomir [10] this paper presents calculation of heat transfer coefficient by using the experimental setup in an internally rifled tube with helical ribs. The experimental set up was installed at the laboratory of Institute of Thermal Power Engineering. The tube specimen used in experiments found application in supercritical circulating Fluidized (CFB) boiler.

Weigo [11] his experiments used Therminol-55 fluid to determine the heat transfer coefficient for helically ribbed tubes which were arranged horizontally. The tube dimensions taken having the inner and outer diameters of 20 and $25 \mathrm{~mm}$ respectively. The height of ribs were $1 \mathrm{~mm}$ and pitch was $12 \mathrm{~mm}$. The conclusion from his experiments is that increase of Reynolds number and friction factor as compared to the smooth pipes. Also the experimental results were compared with modelling results.

Majewski K [12] this paper presented the linear pressure drop and friction losses for the fluid flow through the internally ribbed tube. The theory of this paper helps to determine heat transfer coefficient and linear frictional losses. The set up used the internally ribbed tube has the following characteristic dimensions. 

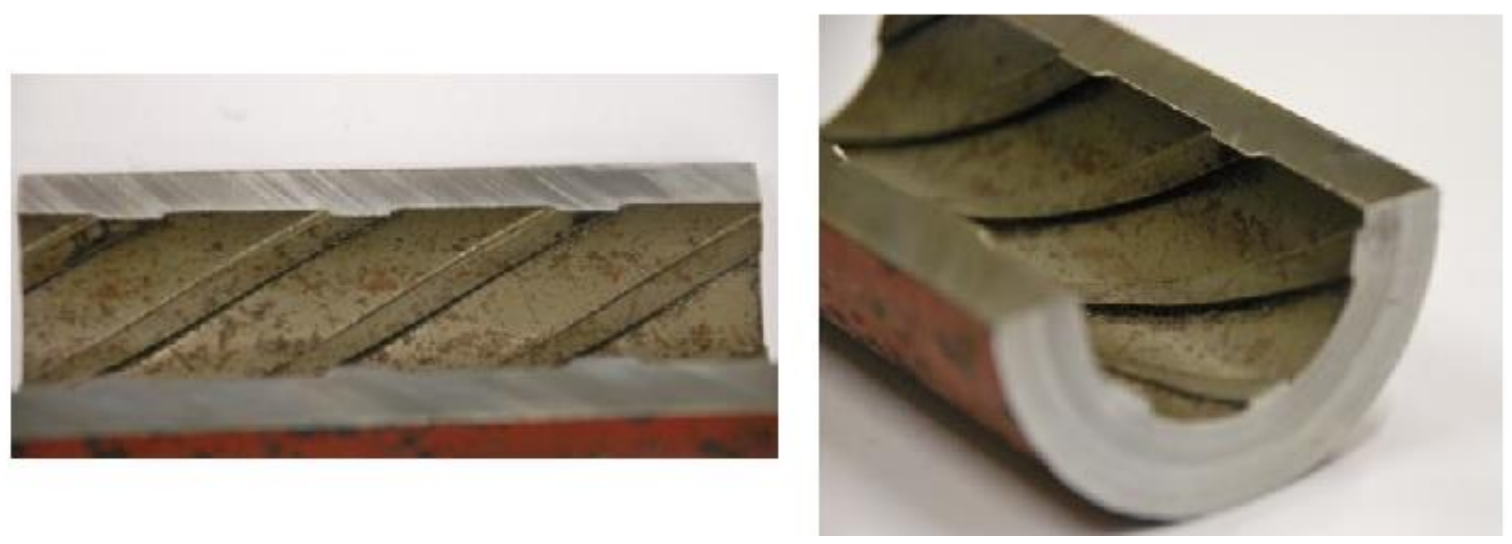

Figure 1 Cross section of the tested tube with internal helical ribs
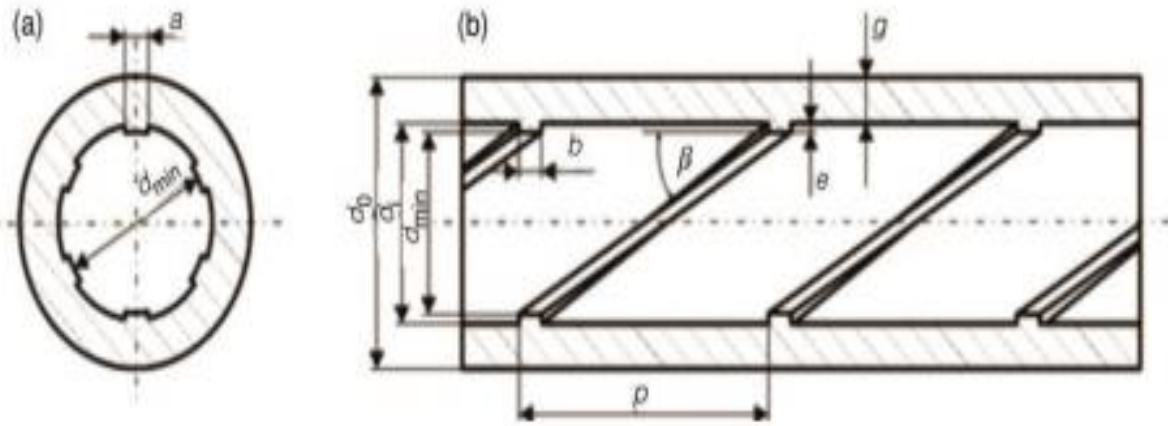

Figure 2 Geometrical dimensions of rifled tubes;

(a) Transverse section and (b) longitudinal section

\section{CONCLUSIONS}

Apart from the research publications aforementioned, experiments have been carried out on tubes with internal helical ribs which related to heat transfer. The experiments are carried out by using different fluids and tubes of different geometries. In industrial heat exchangers and in air conditioning installations such tubes are common with internal diameter less than 20 $\mathrm{mm}$. Hence most of the studies have been taken for research purpose tubes with internal helical ribs with less than $20 \mathrm{~mm}$ internal diameter. Initially tests were carried out by using air. Later on, the working medium water is used under different pressures or cooling agents. For this reason continuous development and optimization of methods are taking place to intensify the heat transfer by using the different cross sections of internal helical ribs, helix angle, rib width and number of ribs.

\section{REFERENCES}

[1] Carnovos, T., Cooling of Air in Turbulent flow with Internally Finned tubes, Heat Transfer Engineering, I (1979), 2, pp. 41 - 46.

[2] Webb, R., Heat Transfer and Friction Characteristics of internal Helical- Rib Roughness, Journal of Heat Transfer, 122 (2000), 1, pp. $134-142$.

[3] Zdaniuk, G., Experimental determination of Heat transfer and Friction in Helically-Finned Tubes, Experimental Thermal and Fluid Science, 32 (2008),3, pp. 761 - 775. 
[4] Pan, J., Experimental Investigation on Heat Transfer Characteristics of Low mass flux rifled Tube with Upward flow, International Journal of Heat and Mass Transfer, 54(2011), 13 - 14, pp. $2952-2377$.

[5] Zhu, X., Self Compensating Characteristic of Steam-water Mixture at Low Mass velocity in vertical upward parallel Internally Ribbed Tubes, Applied Thermal Engineering, 30 (2010), 16 , pp. $2370-2377$.

[6] Li, Z., Improved Gas heaters for Super critical $\mathrm{CO}_{2}$ Rankine cycles: Considerations on Forced and Mixed convection heat Transfer Enhancement, Appl Energy, 178 (2016), Sept, pp. 126 141.

[7] Yang, Z., Numerical study on the Heat Transfer Enhancement of Supercritical $\mathrm{CO}_{2}$ in vertical Ribbed Tubes, Appled Thermal Engineering, 145 (2018), Dec, pp.705 - 715.

[8] Xu, W., Experimental and Numerical Investigation on Heat Transfer of Therminol heat Transfer Fluid in an Internally Four-head Ribbed Tube, International Journal of Thermal Sciences, 116 (2017), June, pp. 32 - 44.

[9] Zhang, Q., Experimental study on Heat Transfer to the Supercritical water Upward Flow in a Vertical Tube with Internal Helical Ribs, International Journal of Heat and Mass Transfer, 89 (2015), Oct ., pp. $1044-1053$

[10] Slawomir, G., Experimental Determination of the Heat Transfer Coefficient in Internally Rifled tubes, Thermal science (2019), Vol 23, Suppl.4, pp. S 1163 - 1174.

[11] Weiguo, X, et al., Simulations and experiments of laminar heat transfer for Therminol heat transfer fluids in a rifled tuve, Appl.Therm.Engg. 2016, 102, pp. $861-872$.

[12] Majewski K., Concept of measurement and test station for determining linear pressure drop and heat transfer coefficient of internally ribbed tubes, J. Power Technology, 93 (5) , pp. $340-$ 346. 